\title{
Have population declines in Egyptian Vulture and Red-headed Vulture in India slowed since the 2006 ban on veterinary diclofenac?
}

\author{
TOBY H. GALLIGAN, TATSUYA AMANO, VIBHU M. PRAKASH, \\ MANDAR KULKARNI, ROHAN SHRINGARPURE, NIKITA PRAKASH, \\ SACHIN RANADE, RHYS E. GREEN and RICHARD J. CUTHBERT
}

\begin{abstract}
Summary
Populations of three vulture species of the genus Gyps, the Egyptian Vulture Neophron percnopterus and Red-headed Vulture Sarcogyps calvus have declined markedly on the Indian subcontinent since the mid-199os and all are now Critically Endangered or Endangered. Gyps vultures have been killed by the widely used non-steroidal anti-inflammatory drug diclofenac, ingested when they feed on carcasses of domesticated ungulates treated with the drug shortly before death. However, it is not known whether Egyptian Vulture and Red-headed Vulture are also sensitive to diclofenac. Veterinary use of diclofenac was banned in India in 2006. Since then, the prevalence and concentration of diclofenac in domesticated ungulates carcasses has decreased and population declines of Gyps vultures have slowed or reversed. Here, we examine counts of Egyptian and Red-headed Vultures obtained on road transects in and near protected areas between 1992 and 2011 . We found indications that the declines in both species appear to have slowed and possibly increased after the ban was introduced, though the small numbers of birds counted make this conclusion less robust than that for the Gyps species. These results suggest that both species may have been adversely impacted by diclofenac and that government bans on this drug, which are beginning to take effect, may benefit a wider range of vulture species in the Indian subcontinent than was previously thought.
\end{abstract}

\section{Introduction}

Beginning in the mid-1990s, five species of vultures have declined rapidly throughout South Asia (Prakash et. al. 2003, 2007, Gilbert et al. 2002, 2006, Green et al. 2004, Cuthbert et al. 2006, Chaudhary et al. 2012). Between 1992 and 2007, road transect counts in India showed that the Oriental White-backed Vulture Gyps bengalensis declined by $>99.9 \%$ and the Long-billed Vulture Gyps indicus and Slender-billed Vulture Gyps tenuirostris combined declined by $96.8 \%$ (Prakash et al.2007). Cuthbert et al. (2006) found an 80.0\% decline in Egyptian Vulture Neophron percnopterus numbers and a 91.0\% decline in the Red-headed Vulture Sarcogyps calvus using road transect surveys in and near protected areas in India between 1991 and 2003. Based on these changes, four of these species are listed as 'Critically Endangered' on the IUCN Red List and the Egyptian Vulture as 'Endangered' (IUCN 2013).

The non-steroidal anti-inflammatory drug (NSAID) diclofenac is highly toxic to Gyps vultures (Oaks et al. 2004, Swan et al. 2006). Vultures are exposed to diclofenac when they feed upon carcasses of domesticated ungulates that have been treated with the drug shortly before death (Oaks et al. 2004, Swan et al. 2006). Green et al. (2004) estimated that less than $0.8 \%$ of ungulate carcasses available to foraging vultures would need to contain a lethal dose of diclofenac for this 
to have caused the observed population declines. Sampling tissues from carcasses of domestic ungulates in India between 2004 and 2005 showed that the proportion contaminated with diclofenac and the concentration of the drug in their tissues were sufficient to have caused vulture declines at the observed rates without the involvement of any other factor (Green et al. 2007).

Efforts to achieve voluntary withdrawal of use of veterinary diclofenac began in 2004. The licence to manufacture veterinary formulations of diclofenac was withdrawn by the Drug Controller General of India in 2006. The ban was adopted in Pakistan and Nepal in the same year and in Bangladesh in 2010. Domesticated ungulate carcass sampling in India since the 2006 ban has shown a decline in the prevalence and concentration of diclofenac in their tissues (Cuthbert et al. 2011) and road transect surveys indicate stabilisation of the populations of Long-billed and Slender-billed Vultures, and a possible increase in the Oriental White-backed Vulture population in India between 2007 and 2011 (Prakash et al. 2012). Similar population increases have been observed in Pakistan (Chaudhry et al. 2012) and Nepal (Prakash et al. 2012).

It is not currently known if Egyptian and Red-headed Vultures are susceptible to diclofenac poisoning. However, both species are likely to show the similar physiological intolerance and exposure risk to diclofenac through a common ancestry and foraging niche with Gyps vultures (see Discussion). In other parts of their range, Egyptian and Red-headed Vultures are threatened by a variety of problems (Ogada et al. 2012), including changes in natural and agricultural systems (Liberatori and Penteriani 2001, Clements et al. 2012), but mainly targeted and non-targeted poison baiting (Hernández and Margalida 2009, Clements et al. 2012) and electrocution on poorly designed power lines (Angelov et al. 2013). These same problems certainly affect South Asian populations to some extent, but do not explain the rapid and widespread declines observed (Prakash et al. 2003, Cuthbert et al. 2006). Alternatively, Green et al. (2004, 2007) demonstrated that diclofenac explained similar rapid and widespread declines in Gyps vultures. Therefore, it is highly likely that the populations of Egyptian and Red-headed Vultures in India have been affected, like Gyps vultures, by the widespread veterinary use of diclofenac and its subsequent ban in 2006.

In this paper, we update a previous analysis of counts of the two species in protected areas in India by Prakash et al. (2003) and Cuthbert et al. (2006), using results from two further surveys in 2007 and 2011. We examine if, as reported for the Gyps vultures, the population declines of Egyptian and Red-headed Vultures have slowed flowing the ban on diclofenac.

\section{Methods}

\section{Vulture surveys}

Vultures were counted along roads within and immediately surrounding protected areas (national parks and wildlife sanctuaries, plus a $25 \mathrm{~km}$-wide buffer zone) in northern India (Table SI). Surveys were first conducted in one of the years between 1991 and 1993, when 14 protected areas were surveyed (Samant et al. 1995). Following Cuthbert et al. (2006) we treat this first survey in the analysis as having occurred in the same year, 1992 . Beginning in 2000, we surveyed 18 protected areas, including the original 14 areas. Each of these 18 protected areas was surveyed in at least two of the years 2000, 2002, 2003, 2007 and 2011; however, not all areas were surveyed in all survey years. The results are shown in Table S 1 in the online Supplementary Materials. Results for years before 2007 are the same as previously reported in Samant et al. (1995), Prakash et al. (2003) and Cuthbert et al. (2006).

Surveys were made between March and June, coinciding with the post-fledging period for both species (Naoriji 2006). Transects were surveyed from a motor vehicle with a driver and an experienced observer. The vehicle was driven at $10-20 \mathrm{~km} / \mathrm{h}$ within protected areas and at $\sim 50 \mathrm{~km} / \mathrm{h}$ in the buffer zones surrounding the protected areas. Across repeated surveys, routes and survey effort were the same. All vultures observed soaring and roosting within $500 \mathrm{~m}$ on each side of roads were recorded. The length of road surveyed in each protected area depended on the size of that protected area. The 1992 survey covered 5,800 km of transects, whilst the later surveys covered 6,800 km. 


\section{Statistical analysis}

Population changes have been usually estimated from count records by fitting a generalised linear model (GLM) with a log link and a Poisson error distribution (Gregory and van Strien 2010). However, the data used in this study include many zero counts as well as a few large values (Table SI). Ignoring such over-dispersion can lead to underestimation of standard errors and misleading inference for the parameters of interest (Okamura et al. 2012). For this reason, we fitted three types of models to each dataset (see below) and compared their performance based on the Akaike Information Criterion (AIC) (Burnham and Anderson 2002). Despite a small ratio between sample size and the number of parameters $(<40)$ for both species, we did not use the second-order AIC (AICc) as this is normally derived assuming Gaussian error distributions and is difficult to compute for other error distributions (Burnham and Anderson 2002). We subsequently calculated AIC difference $\left(\Delta_{i}\right)$ and Akaike weight $\left(w_{i}\right)$ for each model, where $\Delta i$ is the difference between the AIC of the $i$ th model and the smallest AIC value in the model set. The ratio of the $\Delta i$ of each model relative to the model set, $w_{i}$, thereby provides a measure of the strength of evidence for each model being the best model. The model with the smallest AIC was defined as the single best model if that model had a $w_{i} \geq 0.9$, and was used to develop population indices. If this was not the case, model averaging was performed by summing parameter estimates weighted by respective $w_{i}$ values across all models.

The first model was a GLM with a log link and a Poisson error distribution (P). In this model, site and year were treated as factors to allow for sites that were not surveyed in every year, the model being $\log _{\mathrm{e}}\left(c_{i j}\right)=g_{i}+h_{j}$, where $c_{i j}$ is the expected value of the count at the $i$ th site in the $j$ th year, $g_{i}$ is the site effect for the $i$ th site, and $h_{j}$ is the year effect for the $j$ th year. Population indices in the $j$ th year, scaled relative to the first year of the series, were calculated as index $x_{j}=\exp \left(h_{j}\right) /$ $\exp \left(h_{1}\right)$.

The second model was a GLM with a log link and a negative binomial error distribution (NB). This model is essentially the same as the P model above, apart from assuming a negative binomial error distribution instead of a Poisson error distribution. The third model was a zero-inflated Poisson (ZIP) model that has two components that correspond to two sources of zeros: the first is based on a binary error distribution that generates excess zeros; and the second component is based on a Poisson error distribution that generates counts, some of which may be zeros. In this study, the first binary component was modelled with a logit link and three different predictors: intercept only, year effect only, and site effect only. Here both site and year effects were not considered together in the binary component as the probability of an excess zero ( $\pi$, see below) is dependent on both sites and years in such a model, making it impossible to estimate population indices that are independent of sites. The second Poisson error component was modelled with the same structure as the Poisson GLMs. Consequently, the model equation is $c_{i j}=\pi \cdot 0+(I-\pi) \cdot \exp \left(\alpha_{i}+\beta_{j}\right)$, where $\pi$ is the probability of an excess zero from the binary error component, and $\alpha_{i}$ and $\beta_{j}$ are the site effect for the $i$ th site and the year effect for the $j$ th year, respectively, from the Poisson error component. Note here that $\pi$ is modelled using any of the three different sets of predictors above. For ZIP models, population indices were calculated as index $x_{j}=c_{i j} / c_{i 1}=\exp \left(\beta_{j}\right) / \exp \left(\beta_{1}\right)$ if the binary component was modelled with intercept only or site effect only, and index $x_{j}=c_{i j} / c_{i 1}=\left(1-\pi_{j}\right) \cdot \exp \left(\beta_{j}\right) /$ $\left(I-\pi_{1}\right) \cdot \exp \left(\beta_{1}\right)$ if it was modelled with year effect only. Since the ZIP model with the smallest AIC did not include the site effect in the binary error component (see Results and Table 1 ), population indices were not affected by the choice of a site in the calculation. Following Fewster et al. (2000), $95 \%$ confidence intervals for the indices were estimated by 999 bootstrap iterations, based on the best model or all models if estimates were obtained through model averaging. For the latter, a proportion of the total bootstrapped samples were obtained for each model based on its $w_{i}$.

We estimated the average annual rate of population change, as a percentage, in the period between two consecutive surveys at times $i$ and $j$, as $100 \cdot\left(\left(\text { index }_{j} / \text { index }_{i}\right)^{1 /(j-i)}-1\right)$ and obtained $95 \%$ confidence limits of these rates by the bootstrap samples. To test whether the annual rate of population change had altered over time, we also calculated a difference in the two successive 
Table 1. The log-likelihood ( $L$ ), number of parameters (K), Akaike Information Criteria (AIC), AIC difference $(\Delta i)$ and AIC weight $(w i)$ for different models fitted to count data of Egyptian Vulture and Red-headed Vulture. The largest $w_{i}$ for each species is shown in bold. The three different types of zero-inflated Poisson models have different predictors in a binary component that are shown in brackets.

\begin{tabular}{|c|c|c|c|c|c|c|}
\hline Species & Model & $L$ & $\mathrm{~K}$ & AIC & $\Delta i$ & $w i$ \\
\hline \multirow[t]{5}{*}{ Egyptian Vulture } & $\mathrm{P}$ & -123.02 & 17 & 280.03 & 60.58 & 0.00 \\
\hline & NB & -106.28 & 18 & 248.57 & 29.12 & 0.00 \\
\hline & ZIP (intercept) & -91.73 & 18 & 219.45 & 0.00 & 0.54 \\
\hline & ZIP (year) & -87.19 & 23 & 220.39 & 0.94 & 0.34 \\
\hline & ZIP (site) & -82.13 & 29 & 222.25 & 2.80 & 0.13 \\
\hline \multirow[t]{5}{*}{ Red-headed Vulture } & $\mathrm{P}$ & -108.14 & 16 & 248.28 & 42.35 & 0.00 \\
\hline & NB & -90.54 & 17 & 215.07 & 9.15 & 0.01 \\
\hline & ZIP (intercept) & -88.78 & 17 & 211.56 & 5.63 & 0.06 \\
\hline & ZIP (year) & -80.96 & 22 & 205.93 & 0.00 & 0.93 \\
\hline & ZIP (site) & -84.83 & 27 & 223.66 & $17 \cdot 73$ & 0.00 \\
\hline
\end{tabular}

estimates of the annual rate of population change and its $95 \%$ confidence limits, using the same bootstrap samples. This calculation was performed only for data after 2000 as population declines may have started part way through the period between 1992 and 2000, potentially causing the estimated annual rate for this period to be biased low.

All models were implemented using R (R Development Core Team 2013) using the packages 'MASS' (Ripley et al. 2013) for NB and GLMs, and 'pscl' (Jackman et al. 2012) for ZIP models.

\section{Results}

The proportion of protected areas (and surrounding buffer zone) in which each species was counted decreased from $57 \%$ in 1992 to $17 \%$ in 2011 for both species (Table $\mathrm{S}_{1}$ ).

ZIP models gave smaller AIC values and consequently larger $w_{i}$ values than the Poisson and NB GLMs for both Egyptian and Red-headed Vultures (Table 1). Regarding the structure of the binary component in the ZIP models, the model with intercept only and year only had the largest $w_{i}$ values for Egyptian Vultures and Red-headed Vultures, respectively (Table 1 ). The ZIP (year) model for Red-headed Vultures had a $w_{i}>0.9$; hence, we estimated population indices and bootstrapped $95 \%$ confidence intervals from this single best model. The ZIP (intercept) model for Egyptian Vultures had a $w_{i}<0.9$; hence, we model averaged estimates and bootstrapped $95 \%$ confidence intervals across all five models.

For both Egyptian and Red-headed Vultures the survey results indicated a substantial population decline between the early 1990 and the early to mid-2000s, with the Egyptian and Redheaded Vulture declining by 91\% (from 1992 to 2007; Figure 1) and 94\% (from 1992 to 2003 Figure 2), respectively. However, there was evidence of a partial recovery in populations of both species in the late 2000 (Figures 1-2). In the 2011 survey, the population indices for Egyptian and Red-headed Vultures were $46 \%$ and $25 \%$ of those in the 1992 survey, respectively; and $75 \%$ and $62 \%$ of those in 2000, respectively. For both species, the population index in 2011 was significantly lower than that in 1992 (percentage change in indices [95\% confidence interval]: -54.11[-100.00, -37.82] for Egyptian Vulture; -75.13 [-98.08, -18.54] for Red-headed Vulture). This was higher than the three previous surveys from 2002 to 2007 , although wide confidence intervals led to these differences being non-significant.

The estimated annual rates of population change showed that the population trend was significantly negative between 1992 and 2002 for both the species, but has turned to positive since 2007 for Egyptian Vulture (Figure 3) and since 2003 for Red-headed Vulture (Figure 4), although for both the species, the $95 \%$ confidence interval overlapped zero, leading to statistically nonsignificant increases. However, for Egyptian Vulture the proportion of bootstrapped samples that showed a positive increase after 2007 (the year the population trend appeared to reverse for this 


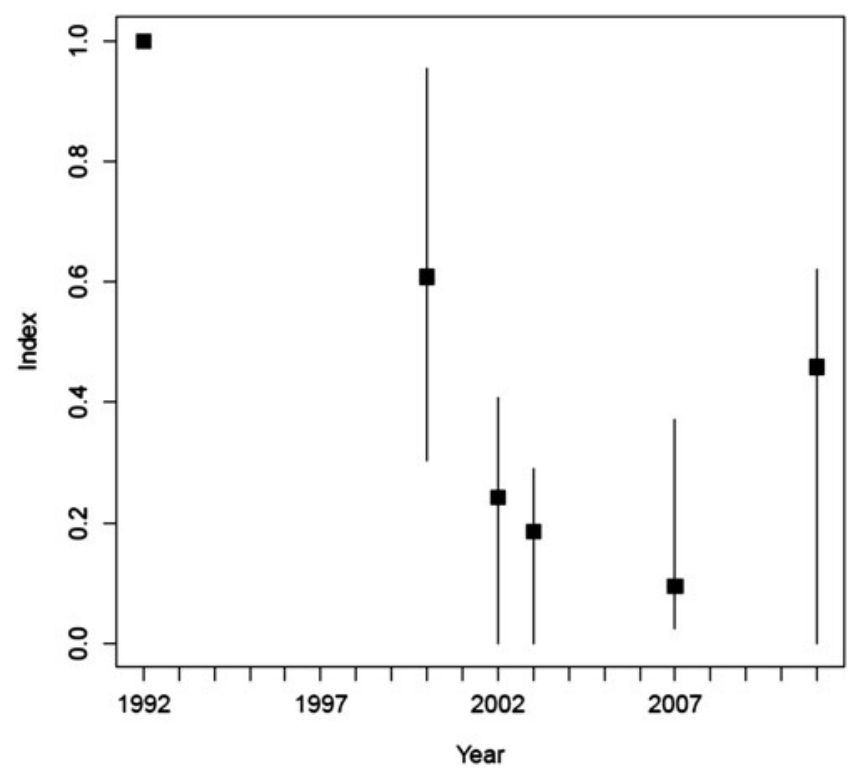

Figure 1. Population index values for Egyptian Vulture surveyed in 18 protected areas in India between 1992 and 2011. Indices are population densities relative to that in 1992, estimated by a zero-inflated Poisson model with only the intercept in the binary component (see Methods for more detail). Vertical lines show estimated $95 \%$ confidence limits.

species; Figure I) was $73 \%$. Similarly, for the Red-headed Vulture the proportion of bootstrapped samples that showed a positive increase after 2003 (the year the population trend appeared to reverse for this species; Figure 2) was $87 \%$.

Changes in the annual rates of population change after 2000 were mostly positive, except the most recent period for Red-headed Vulture (Egyptian Vulture: 2000-2002 to 2002-2003 = 13.7; $2002-2003$ to $2003-2007=7.6$; and 2003-2007 to 2007-2011 $=64 \cdot 3$. Red-headed Vulture: $2000-$ 2002 to $2002-2003=13.6 ; 2002-2003$ to $2003-2007=65.3$; and $2003-2007$ to $2007-2011=-11.7$ ). However, the $95 \%$ confidence interval overlapped zero in all cases.

\section{Discussion}

The declines in Egyptian and Red-headed Vulture populations in India between the 199os and early to mid-2ooos appear to have slowed. Specifically, our results suggest that for both species the probability of population increases, based on the proportion of bootstrapped samples that showed a positive population increase, is higher than the probability of population declines.

Our estimates of population trends are imprecise because the numbers of each species encountered on each survey and the numbers of sites surveyed were small, particularly in later years; reinforcing the point that while the declines appear to have slowed, populations remain small. In addition, vulture observations were increasingly concentrated in a small number of sites. For example, 33 of the 42 Egyptian and 27 of the 30 Red-headed Vultures counted in 2011 were counted in a single, but different, protected area (Desert and Bandhavgarh National Parks, respectively; Table SI). These considerations resulted in wide confidence intervals for the estimated population indices and annual rates of change, preventing us from concluding with certainty that both the species have indeed begun to increase. Therefore, we cannot exclude the possibility that populations of these two vulture species in the whole of India are continuing to decline. Further, the apparent annual rate of population increase should be treated with caution due to the point estimate 


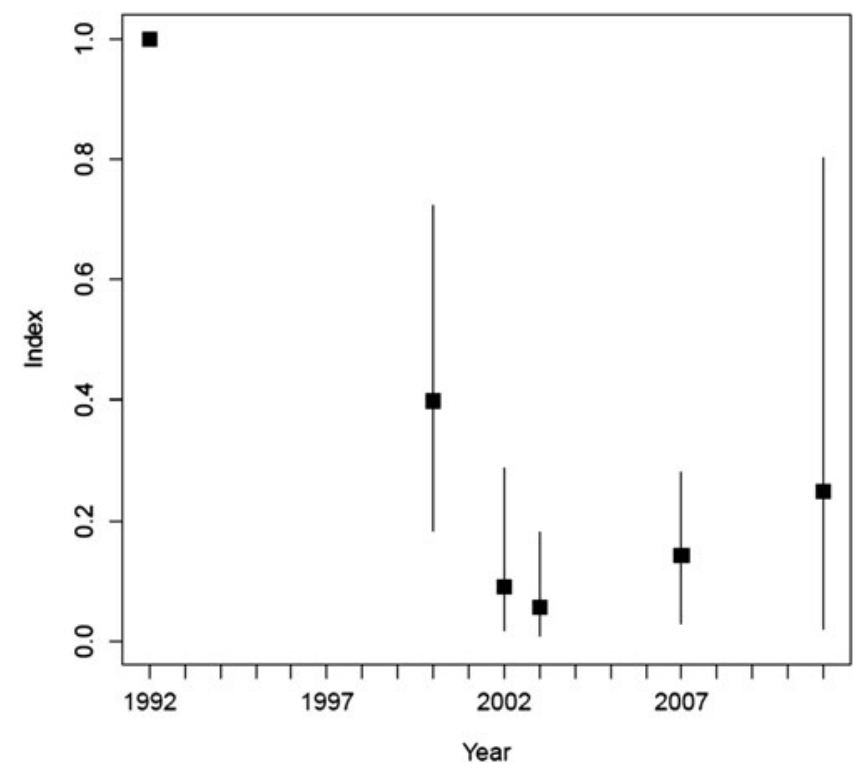

Figure 2. Population index values for Red-headed Vulture surveyed in 18 protected areas in India between 1992 and 2011. Indices are population densities relative to that in the 1992, estimated by a zero-inflated Poisson model with the year effect in the binary component (see Methods for more detail). Vertical lines show estimated $95 \%$ confidence limits.

for the rate of increase in Egyptian Vultures from 2007 to 2011 (Figure I) is beyond the maximum growth that is likely for a long-lived raptor species ( $10 \%$ per year; Niel and Lebreton 2005$)$. Despite these caveats, the available evidence indicates that populations of both species are no longer declining as rapidly as they were in the early 2000 .

Two areas of high vulture numbers (Desert and Bandhavgarh National Parks) no doubt contributed greatly to our estimates of population increases in 2011. However, we have no reason to think that counts in these areas, in that year, were anomalies. In fact, comparable numbers of Egyptian Vulture have been counted in the Desert National Park in past surveys (see Table $\mathrm{S}_{1}$ ); and Bandhavgarh National Park was known to support large numbers of Red-headed Vultures prior to the species' decline (V. Prakash unpubl. obs). Unfortunately we first surveyed the latter park after the decline in the species had begun (2000). These parks appear to contain good habitat for the respective species and therefore it is reasonable to assume, if populations are increasing, that we would see increases in these parks first. We are unaware of supplementary interventions for recovery of either species at these sites. However, we do know that the extent of diclofenac use differs geographically (Cuthbert et al. 2011); hence, its use in these particular sites might be lower than in elsewhere.

Our results for Egyptian Vulture and Red-headed Vulture resemble recent changes in population trends of Oriental White-backed, Long-billed and Slender-billed Vultures in India and Nepal (Prakash et al. 2012). The slowing of the declines in these three species of Gyps vultures in India coincided with the introduction in 2006, and increasing effectiveness, of a ban on the veterinary use of diclofenac. The magnitude of the observed, recent, positive change in population trend in India of the Oriental White-backed Vulture is consistent with that predicted from reductions in the level of diclofenac contamination of domesticated ungulate carcasses observed after the ban (Cuthbert et al. 2011, Prakash et al. 2012). Although there is no direct evidence that either Egyptian or Red-headed Vultures are sensitive to diclofenac toxicity, the reduction in diclofenac contamination of domesticated ungulate carcasses in India may have also benefitted these species. 


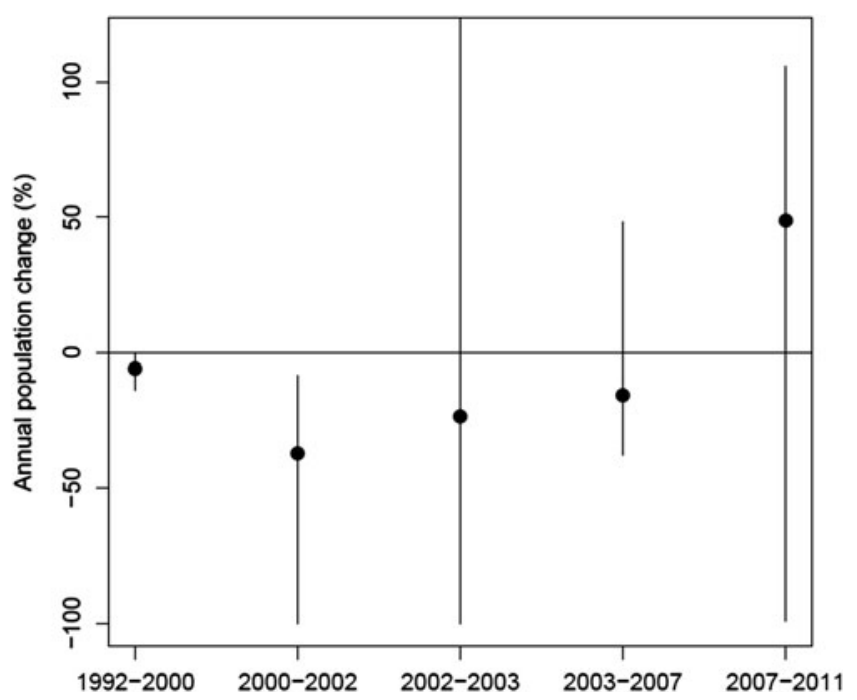

Figure 3. The rate of population change (\% per year) of Egyptian Vulture. Circles show average annual rates between each pair of consecutive surveys with their $95 \%$ bootstrap confidence intervals (vertical lines). Note that the upper confidence limits for 2002-2003 (130.05) go beyond the range of the figure.

There are two forms of evidence that support the idea that diclofenac poisoning has caused the observed declines in Egyptian and Red-headed Vultures: 1) a common ancestry with Gyps vultures (Griffiths et al. 2007); and 2) an overlapping diet with Gyps vultures (Naoroji 2006). Recent evidence of diclofenac residue and visceral gout in non-Gyps scavenging raptor species

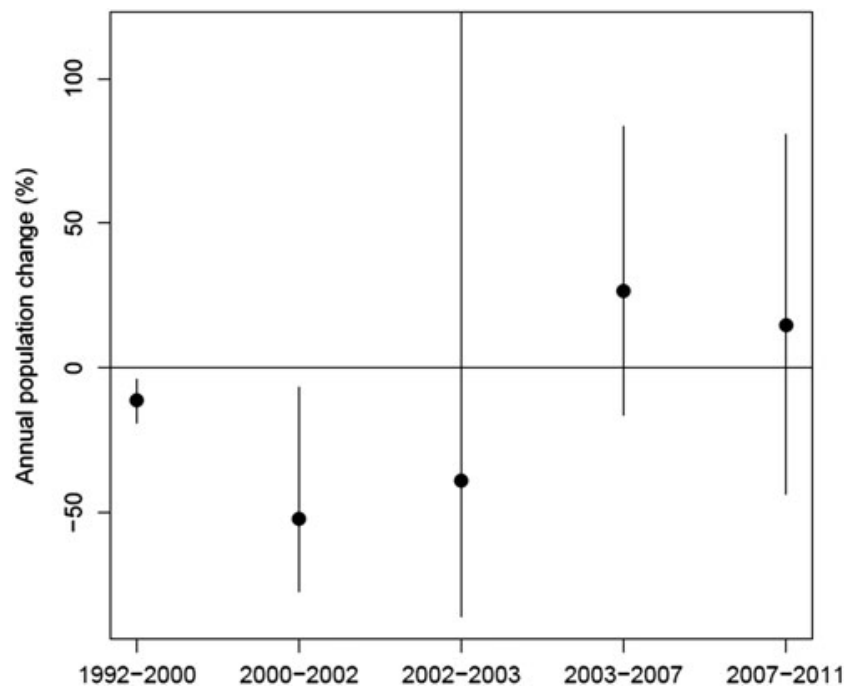

Figure 4. The rate of population change (\% per year) of Red-headed Vulture. Circles show average annual rates between each pair of consecutive surveys with their $95 \%$ bootstrap confidence intervals (vertical lines). Note that the upper confidence limits for 2002-2003 $\left(5.66 \cdot 10^{9}\right)$ goes beyond the range of the figure. 
found dead in Indian carcass dumps suggest that a greater diversity of Accipitridae species may be susceptible to diclofenac poisoning than earlier thought (Sharma et al. in this issue). Further, despite having wider foraging niches than Gyps vultures (which specialise on large ungulates), both the Egyptian and Red-headed Vultures certainly feed on domesticated ungulate carcasses and may have increased this source of food in their diet in the wake of the Gyps vulture declines (Cuthbert et al. 2006). We have no data on causes of individual mortality for either Egyptian or Red-headed Vultures, and acknowledge that vulture species worldwide face numerous threats, but know of no threat, other than diclofenac poisoning, that could have caused such large and widespread declines as those observed in these species during the 1990 s to early $2000 \mathrm{~s}$ (see Green at al. 2004, 2007).

Confirmation of the sensitivity to diclofenac of both Egyptian and Red-headed Vultures is needed in order to verify that the nationwide reduction in diclofenac contamination is indeed responsible for the slowing of population declines in these species. Nonetheless, our results show more encouraging population trends for two more threatened vulture species in India, after the 2006 ban on veterinary diclofenac.

\section{Supplementary Material}

The supplementary materials for this article can be found at journals.cambridge.org/bci

\section{Acknowledgements}

We thank the Ministry of the Environment and Forests (Government of India) for their support in conducting this research. Financial support: The UK Government Department of Environment, Food and Rural Affairs' Darwin Initiative (18-0o8) and the Royal Society for the Protection of Birds.

\section{References}

Angelov, I., Hashim, I. and Oppel, S. (2013) Persistent electrocution mortality of the Egyptian Vulture Neophron percnopterus over 28 years in East Africa. Bird Conserv. Internatn.23: 1-6.

Burnham, K. P. and Anderson, D. R. (2002) Model selection and multimodel inference: a practical information-theoretic approach. $2^{\text {nd }}$ Edition. New York: Springer-Verlag.

Chaudhary, A., Subedi, T. S., Giri, J. B., Baral, H. S., Bidari, B., Subedi, H., Chaudhary, B., Chaudhary, I., Paudel, K. and Cuthbert, R. J. (2012) Population trends of critically endangered Gyps vultures in the lowlands of Nepal. Bird Conserv. Internatn. 22: 270-278.

Chaudhry, J. M. I., Ogada, D. L., Malik, R. N., Virani, M. Z. and Giovanni, M. D. (2012) First evidence that populations of the critically endangered Long-billed Vulture Gyps indicus in Pakistan have increased following the ban of the toxic veterinary drug diclofenac in South Asia. Bird Conserv. Internatn. 22: 389-397.
Clements, T., Gilbert, M., Rainey, H. J., Cuthbert, R., Eames, J. C., Bunnat, P., Teak, S., Chansocheat, S. and Setha, T. (2012) Vultures in Cambodia: population, threats and conservation. Bird Conserv. Internatn. 23: 7-24.

Cuthbert, R. J., Green, R. E., Ranada, S., Saravanan, S., Pain, D., Prakash, V. and Cunningham, A. A. (2006) Rapid population declines of Egyptian Vulture (Neophron percnopterus) and Red-headed Vulture (Sarcogyps calvus) in India. Anim. Conserv. 9: 349-354. Cuthbert, R., Taggart, M. A., Prakash, V., Saini, M., Swarup, D., Upreti, S., Mateo, R., Chakraborty, S. S., Deori, P. and Green, R. E. (2011) Effectiveness of action in India to reduce exposure of Gyps Vultures to the toxic veterinary drug diclofenac. PLoS One 6: e19069.

Fewster, R. M., Buckland, S. T., Siriwardena, G. M., Baillie, S. R. and Wilson, J. D. (200o) Analysis of population trends for farmland birds using generalized additive models. Ecology 81: 1970-1984. 
Gilbert, M., Virani, M. Z., Watson, R. T., Oaks, J. L., Benson, P. C., Khan, A. A., Ahmed, S., Chaudhry, J., Arshad, M., Mahmood, S. and Shah, Q. A. (2002) Breeding and mortality of oriental white-backed vulture Gyps bengalensis in Punjab Province, Pakistan. Bird Conserv. Internatn. 12: 311-326.

Gilbert, M., Watson, R. T., Virani, M. Z., Oaks, J. L., Ahmed, S., Chaudhry, M. J. I., Arshad, M., Mahmood, S., Ali, A. and Khan, A. A. (2006) Rapid population declines and mortality clusters in three Oriental White-backed Vulture Gyps bengalensis colonies in Pakistan due to diclofenac poisoning. Oryx 40: 388-399.

Green, R. E., Newton, I., Shultz, S., Cunningham, A. A., Gilbert, M., Pain, D. J. and Prakash, V. (2004) Diclofenac poisoning as a cause of vulture population declines across the Indian subcontinent. J. Appl. Ecol. 41: 793-800.

Green, R. E., Taggart, M. A., Senacha, K. R., Raghavan, B., Pain, D. J., Jhala, Y. and Cuthbert, R. (2007) Rate of decline of the oriental White-backed vulture Gyps bengalensis population in India estimated from measurements of diclofenac in carcasses of domesticated ungulates. PloS One 2: e686.

Gregory, R. D. and van Strien, A. (2010) Wild bird indicators: using composite population trends of birds as measures of environmental health. Ornithol. Sci. 9: 3-22.

Griffiths, C. S., Barrowclough, G. F., Groth, J. G. and Mertz, L. A. (2007) Phylogeny, diversity and classification of the Accipitridae based on DNA sequences of the RAG-I exon. J. Avian Biol. 38: 587-602.

Hernández, M. and Margalida, A. (2009) Poisonrelated mortality effects in the Endangered Egyptian Vulture (Neophronpercnopterus) population in Spain. Eur. J. Wildl. Res. 55: 415-423.

IUCN (2013) The IUCN Red List of threatened species. Version $2013.2<$ http://www.iucnred list.org/details/23179/o>. Downloaded on 21 November 2013.

Jackman, S., Tahk, A., Zeileis, A., Maimone, C. and Fearon, J. (2012) pscl. Stanford: Political Science Computational Laboratory, Stanford University (Available at: http://cran.r-project. org/web/packages/pscl/index.html).

Liberatori, F. and Penteriani, V. (2001) A longterm analysis of the declining population of the Egyptian Vulture in the Italian peninsula: distribution, habitat preference, productivity and conservation implications. Biol. Conserv. 101: $381-389$.

Naoroji, R. (2006) The birds of prey of the Indian Subcontinent. London, UK: Christopher Helm/A\&C Black Publishing.

Niel, C. and Lebreton, J-D. (2005) Using demographic invariants to detect overharvested bird populations from incomplete data. Conserv. Biol. 19: 826-835.

Oaks, J. L., Gilbert, M., Virani, M. Z., Watson, R. T., Meteyer, C. U., Rideout, B. A., Shivaprasad, H. L., Ahmed, S., Chaudhry, M. J., Arshad, M., Mahmood, S., Ali, A. and Khan, A. A. (2004) Diclofenac residues as the cause of vulture population decline in Pakistan. Nature 427: 630-633.

Ogada, D. L., Keesing, F. and Virani, M. Z. (2012) Dropping dead: causes and consequences of vulture population declines worldwide. Ann. N. Y. Acad. Sci. 1249: 57-71.

Okamura, H., Punt, A. and Amano, T. (2012) A generalized model for overdispersed count data. Popul. Ecol. 54: 467-474.

Prakash, V., Pain, D. J., Cunningham, A. A., Donald, P. F., Prakash, N., Verma, A., Gargi, R., Sivakumar, S. and Rahmani, A. R. (2003) Catastrophic collapse of Indian whitebacked Gyps bengalensis and long-billed Gyps indicus vulture populations. Biol. Conserv. 109: 381-390.

Prakash, V., Green, R. E., Pain, D. J., Ranade, S. P., Saravanan, S., Prakash, N., Venkitachalam, R., Cuthbert, R., Rahmani, A. R. and Cunningham, A. A. (2007) Recent changes in populations of resident Gyps vultures in India. J. Bombay Nat. Hist. Soc. 104: 127-133.

Prakash, V., Bishwakarma, M. C., Chaudhary, A., Cuthbert, R., Dave, R., Kulkarni, M., Kumar, S., Paudel, K., Ranade, S., Shringarpure, R. and Green, R. (2012) The population decline of Gyps vultures in India and Nepal has slowed since the veterinary use of diclofenac was banned. PLOS ONE 7: e49118.

R Development Core Team (2013) R: A language and environment for statistical computing. Vienna, Austria: R Foundation for Statistical Computing. http://www. r-project.org 
Ripley, B., Venables, B., Hornik, K., Gebhardt, A. and Firth, D. (2013) MASS: support functions and datasets for Venables and Ripley's MASS (Available at: http://cran.r-project. org/web/packages/MASS/index.html).

Samant, J. S., Prakash, V. and Naoroji, R. (1995) Ecology and behaviour of resident raptors with special reference to endangered species. Final report to the U.S. Fish and Wildlife Service. Mumbai, India: Bombay Natural History Society. Grant number 14-1600009-90-125.

Sharma, A. K., Saini, M., Singh, S. D., Prakash, V., Das, A., Dasan, B. R., Pandey, S., Bohara,
D. L., Galligan, T. H., Green, R. E., Knopp, D. and Cuthbert, R. J. (In press) Diclofenac is toxic to the Steppe Eagle Aquila nipalensis: widening the diversity of raptors threatened by NSAID misuse. Bird Conserv. Internatn. doi:10.1017/S0959270913000609.

Swan, G. E., Cuthbert, R., Quevedo, M., Green, R. E., Pain, D. J., Bartels, P., Cunningham, A. A., Duncan, N., Meharg, A. A., Oaks, J. L., Parry-Jones, J., Shultz, S., Taggart, M. A., Verdoorn, G. and Wolter, K. (2006) Toxicity of diclofenac to Gyps vultures. Biol. Lett. 2: $279-282$.

\section{TOBY H. GALLIGAN*, RICHARD J. CUTHBERT}

RSPB Centre for Conservation Science, Royal Society for the Protection of Birds, The Lodge, Sandy, Bedfordshire, UK.

\section{TATSUYA AMANO, RHYS E. GREEN}

Conservation Science Group, Department of Zoology, University of Cambridge, Cambridge, Cambridgeshire, UK.

\section{VIBHU M. PRAKASH, MANDAR KULKARNI, ROHAN SHRINGARPURE, NIKITA} PRAKASH, SACHIN RANADE

Bombay Natural History Society, Hornbill House, S.B. Singh Road, Mumbai, India.

*Author for correspondence; email: toby.galligan@rspb.org.uk

Received 31 May 2013; revision accepted 23 October 2013 Published online I April 2014 